\title{
2. Mediated health citizenships: living with HIV and engaging with the Global Fund in the Gambia
}

\author{
REBECCA CASSIDY AND MELISSA LEACH
}

\section{Introduction}

The early twenty-first century is witnessing a new era of globalism in public health. The last decade has seen an array of new international initiatives and funding mechanisms, driven both by moral concerns with poverty and disease in poorer countries of the global South, and by Northern self-interest and mutual concern in an interdependent world in which not just money and finance, but also people and microbes, are highly mobile. Associated with new patterns of authority and institutional arrangements, these signal emerging dimensions of governance which challenge the pre-eminence of nation-states, yet connect with government institutions in new ways.

This chapter focuses on how such changing patterns of power and governance are unfolding in relation to HIV and AIDS, and how they have been manifested in the small West African country of the Gambia. ${ }^{1}$ It explores how this changing landscape affected the meanings, practices and expressions of citizenship open to and performed by Gambians living with HIV, and the processes of inclusion and exclusion - of people and perspectives - that ensued. The chapter thus offers a particular lens on local-global citizen engagement. We understand this phrase to refer both to the intersection of globalized and localized expectations and practices around rights, knowledge and behaviour; and to how and how far people in local settings can exert claims and priorities in relation to global institutions and arenas. As we argue, these processes are linked, and the politics of mediation are central to both.

HIV provides an apt focus for considering such changing local-global engagements in the health field. What was, in the 1980s, seen as an emergency epidemic is now widely understood to have transformed into a 'long-wave event' with prevention and treatment opportunities and challenges more akin to a chronic disease. The global community has established three new funding mechanisms which are shaping programmes around the world: the Global Fund to Fight AIDS, Tuberculosis 
and Malaria (GFATM); the US President's Emergency Plan for AIDS Relief (PEPFAR); and the World Bank's Multi-Country AIDS Programme (MAP). In the early twenty-first century, these three funders have been providing the majority (57 per cent in 2004) of all donor resources to combat HIV and AIDS (Bernstein and Sessions 2007). By 2007 the GFATM alone had committed US\$ 7.7 billion in 136 countries. $^{2}$ As Robins (this volume) emphasizes, the 'antiretroviral revolution' and HIV prevention programmes enabled by such funding have dramatically extended the reach of global biomedicine across African countries.

One of these countries was the Gambia, and it is the operations of the Global Fund (GFATM) there which are our particular focus. In a context of high national dependence on global funding, the engagement of the GFATM between 2000 and 2006 unleashed a new political economy of resource allocation, a new set of institutional arrangements and opportunities for mediation by state and non-governmental structures, and a new politics of knowledge around the meaning of disease. These have engaged with a particular disease context - in which, with HIV infection rates currently below 5 per cent, ${ }^{3}$ living with HIV is still a socially unusual experience - and a particular political-economic context. Notable features of the latter include President Jammeh's democratically elected yet authoritarian regime, ${ }^{4}$ a long history of international donor and NGO involvement in developmental affairs, and two decades of intensifying neoliberal policies which have prioritized private business entrepreneurs and the coastal tourist industry, leaving the majority of Gambians in deep poverty and a grinding everyday struggle for livelihoods.

Emerging forms and practices of local-global citizen engagement around HIV and AIDS very much reflect this context. For people living with HIV in the Gambia, treatment support groups linked to the GFATM offer to some extent new axes of identity as 'global therapeutic citizens'. In this vein, Robins (this volume) emphasizes the potential of healthrelated activism, strong illness identities and the scarcity of treatment to shape new subjectivities and types of health/biological citizenship, albeit in non-linear and mediated ways. In analysing HIV activism in Burkina Faso, Nguyen describes a 'biopolitical citizenship' that he calls 'therapeutic citizenship', encompassing 'claims made on a global social order on the basis of a therapeutic predicament' (2005: 126). Nguyen's emphasis on the broader industry that has arisen around HIV issues, the heterogeneous conglomeration of different actors and the activation of global networks suggests the emergence of forms of civil society mobilization whose alliances transcend national boundaries and connect local groups to key global players and knowledge. He argues that HIV has 
been able to bring together a range of different phenomena - from condom demonstrations and $\mathrm{CD}_{4}$ counts $^{5}$ to sexual empowerment and an ethic of individual sexual responsibility and compliance with drug regimes - into a stable, worldwide formation. These new global networks have helped to produce a form of therapeutic citizenship based on being HIV positive (biological), together with (political) claims to rights such as access to treatment, and (ethical) ways of integrating being HIV positive into a moral order. Yet in the Gambian context, amid poverty and the particular character of NGO and state mediation, what we see is less an image of active, treatment-rights-claiming, therapeutic citizens. Rather, a close examination of the meanings of support group membership from the perspectives of people living with HIV reveals instead a less empowered conformity to global discourses and procedures as a route to particular sorts of 'getting by'.

This chapter has three main sections. Initially we trace key elements of the changing landscape of power and governance linked to the GFATM, first in brief general terms and then as manifested in the Gambia. We then shift focus to 'see like a citizen', examining the meanings of this configuration from the perspectives of people living with HIV. People's engagement with and experiences of mediating structures (treatment support groups and NGOs) and the politics of knowledge (notions of disease and treatment) are considered in particular depth. In this context, the chapter concludes by reflecting on the axes of inclusion and exclusion emerging in this case, and their implications for current discourses around global therapeutic/health citizenship.

\section{The Global Fund and shifting health governance structures}

The GFATM is part of a new generation of global philanthropy, and a new era of global governance in health. International health has always relied to some extent on non-statist forms of authority. International organizations such as the World Health Organization (WHO) and Centres for Disease Control have long, in practice, overridden national sovereignty in the name of claimed universal goals of disease eradication and prevention (e.g. White 2005). Yet what is emerging today appears different in several important respects. First, the sheer size, scope and resources of the health programmes concerned. Second, the predominance of private, philanthropic and hybrid public-private arrangements, rather than international ones accountable to member states. And third, the moral authority that global health programmes can now exert in a globalized world of mobile people and microbes, where fears of epidemic spread and ideas of global health security abound (Dry 2008). 